\title{
VIDEO PROFILE SEBAGAI SARANA INFORMASI DAN PROMOSI STUDIO SATU PT. MEDIA TELEVISI INDONESIA ( METRO TV )
}

\author{
Lusyani Sunarya ${ }^{1}$ \\ Della Nurasiah ${ }^{2}$ \\ Firmansyah Agustian ${ }^{3}$
}

\begin{abstract}
Dosen STMIK Raharja Tangerang ${ }^{1}$, Mahasiswa STMIK Raharja Tangerang ${ }^{2,3}$
J1.Jendral Sudirman No.40, Modernland, Tangerang 1,2,3

Email : lusyani@ raharja.info', della@ raharja.info ${ }^{2}$, agustian@ raharja.info ${ }^{3}$
\end{abstract}

\begin{abstract}
ABSTRAK
Teknologi khususnya di bidang multimedia, audio visual, dan broadcasting terikat oleh teknologi-teknologi komputer yang berperan cukup penting untuk mendapatkan informasi yang dibutuhkan. Saat ini media informasi dan promosi yang digunakan Studio Satu Metro TV, hanya berupa brosur dan melalui website resmi PT. Metro TV, dengan mengandalkan media informasi dan promosi tersebut di rasa belum cukup untuk di tunjukan kepada audience, yang tentunya menginginkan penyajian informasi yang sangat efektif, akurat, dan menarik untuk dilihat dari segi tampilan maupun isi. Informasi dan promosi yang akan disampaikan pada Studio Satu Metro TV cukup banyak, meliputi : kegiatan kameraman, pengenalan alat switcher, master control room dan lain-lain. Media video profile ini bertujuan agar minat masyarakat pada sebuah informasi akan semakin meningkat. Penyampaian media promosi dan informasi dirancang sesuai dengan bentuk video profile yang menggabungkan audio dan visual, yang menunjukan keseluruhan informasi yang berkaitan pada Studio Satu PT. Media Televisi Indonesia biasa disebut PT.Metro TV. Metodologi penelitian ini menggunakan analisa permasalahan, pengumpulan data, analisa perancangan dan konsep produksi media (KPM) yang meliputi : pre production, production, dan post production. Media yang tepat untuk menunjang informasi dan promosi Studio Satu PT. Metro TV adalah menggunakan video profile, dengan media video profile ini diharapkan dapat menunjang beberapa akses informasi yang jelas, akurat, dan detail, sehingga dapat berguna dan bermanfaat bagi audience yang berminat untuk mengetahui informasi tentang Studio Satu PT. Metro TV, dan video profile ini diharapkan dapat meningkatkan image pada Studio Satu PT. Metro TV.
\end{abstract}

Kata Kunci : Video Profile, Infomasi, Promosi

\begin{abstract}
Technology, especially in the areas of multimedia, audiovisual and broadcasting bound by the computer technologies that play a role important enough to get the needed information. This time information and promotional media used Studio One Metro TV, only in the form of brochures and through the official website of PT. Metro TV, by relying on the information and promotional media in a sense is not enough for the show to the audience, who would want a highly effective presentation of information, accurate, and interesting to look at in terms of look and content. Information and promotion will be presented at Studio One Metro TV quite a lot, include: activities cameraman, introduction switcher tool, master control
\end{abstract}


room and others. Media video profile is intended that the public interest in an information will increase. Submission of media and information campaign designed to match the shape of the video profile that combines audio and visual, which shows the entire information relating to the Studio One PT. Media Televisi Indonesia commonly called PT.METRO TV. Methodology This study uses analysis of the problem, data collection, analysis, design and media production concept (KPM) which includes: pre-production, production and post production. The right media to support information and promotion of Studio One PT. Metro $T V$ is using a video profile, with this profile video media is expected to support some access to information that is clear, accurate, and detailed, so it can be useful and beneficial to the audience who are interested to find out information about Studio One PT. Metro TV, and video profile is expected to improve the image in Studio One PT. Metro TV.

Keywords: Video Profile, information, promotion

\section{PENDAHULUAN}

Media penyiaran dan informasi saat ini berkembang dengan cukup pesat, media tersebut selalu berusaha untuk menampilkan teknologi modern yang dikemas dengan menarik, sesuai dengan kebutuhan audience yang melihatnya. Perkembangan teknologi dalam dunia penyiaran sudah sangat maju, hal itu terbukti dengan adanya alat-alat penunjang dalam melakukan siaran liputan sebuah berita melalui berbagai sumber, selain itu kini tersedia kendaraan yang digunakan untuk melakukan siaran secara langsung. Informasi yang terpercaya sangat dibutuhkan, baik itu seperti melalui media cetak ataupun elektronik. Pada media elektronik, yaitu dengan cara melihat berita secara langsung melalui televisi maupun secara online.

Media elektronik saat ini sangat dibutuhkan, karena mudah dinikmati kapanpun dan dimanapun, sehingga menjadikan PT. Media Televisi Indonesia yang biasa disebut dengan Metro TV,yang beralamat di Jl.Pilar Mas Raya Kav. A-D Kedoya Selatan - Kebon Jeruk, Jakarta Barat 11015, menyajikan informasi berita secara terpercaya selama 24 jam, dimana informasi berita ini dikemas secara baik dan bermanfaat, agar mampu memenuhi keinginan masyarakat akan informasi secara langsung dan terpercaya. Dengan adanya informasi langsung, masyarakat menjadi lebih mudah mengetahui informasi yang tersedia di tempat lain secara langsung melalui televisi.

PT. Media Televisi Indonesia (Metro TV) memiliki 2 studio, yaitu Studio Satu dan Studio Dua yang menyiarkan berbagai program acara. Pada studio 2, sejumlah acara yang disiarkan yaitu tentang talkshow atau berita ringan yang bersifat taping, dan terkadang siaran secara langsung. Sedangkan dalam Studio Satu, acara yang disiarkan selama 24 jam. Siaran yang dibawakan penuh dengan berita atau bulettin. Dalam Studio Satu, terdapat berita yang di siarkan secara langsung dan formal, seperti : Berita Metro Pagi, Berita Metro Kini, Metro Siang hari, Metro Sore hari, Metro Hari Ini, dan Metro Malam hari. Untuk berita yang di siarkan secara informal seperti : Berita Bincang pagi, Wide Shoot, 8-11 Show, dan Metro Sport. Acara berita tersebut, di siarkan secara langsung sesuai dengan jadwal dan jam yang sudah ditentukan, beserta crew yang bertugas. Dalam Studio Satu ada beberapa kameraman, Lightingman, Audioman, Floor Director, Controlling, dan lain-lain.

Saat ini Studio SatuMetro TV media penunjang informasi dan promosi yang digunakan dalam bentuk brosur dan melalui website resmi PT. Metro TV. Dengan mengandalkan sejumlah media informasi dan promosi tersebut di rasa belum cukup untuk di tunjukan kepada masyarakat ataupun mahasiswa saat di adakannya kegiatan workshop di berbagai 
kampus. Studio Satu menginginkan adanya media penunjang informasi dan promosi untuk menginformasikan tentang pengenalan dunia kameraman, alat-alat dalam dunia penyiaran seperti :switcher, master control room dan lain-lain. Selain itu terdapat juga sejumlah kegiatan dan aktifitas yang berlangsung di Studio Satu. Untuk itu Strudio Satu PT. Metro TV membutuhkan sebuah media video profile, agar dapat memberikan informasi dan promosi akurat serta detail mengenai ruang lingkup Studio Satu secara menyeluruh. Adapun informasi yang dibutuhkan ini nantinya bertujuan untuk menopang berbagai kegiatan seperti persentasi dengan klien ataupun sejumlah partner dari PT. Metro TV yang ingin melihat dan mengetahui Studio Satu secara menyeluruh, dan juga untuk membantu pihak Metro TV dalam menunjang acara workshop ke kampus-kampus yang ada di Indonesia, serta turut mengajak partisipasi dari mahasiswa/I yang berminat untuk menjadi salah satu crew di PT. Metro TV.

Perancangan video profile ini diharapkan mampu menunjang berbagai kegiatan baik dalam memberikan informasi atau sebagai promosi mengenai Studio Satu PT. Metro TV. Video profile ini dirancang dengan cara menggabungkan gambar, suara, musik, dan juga berisikan informasi seperti sejarah, visi misi, serta keunggulan, dan informasi lain yang terkait dengan Studio Satu PT. Metro TV dengan penggabungan effect - effect visual ini, diharapkan video profile tersebut dapat meningkatkan minat audience yang melihatnya. Melalui perancangan video profile ini, diharapkan dapat bermanfaat khususnya bagi Studio Satu pada PT. Metro TV, relasi perusahaan, masyarakat, maupun sebagai media penunjang kegiatan workshop untuk para mahasiswa yang tertarik dengan Studio Satu PT. Metro TV.

\section{PERMASALAHAN}

Saat ini media informasi dan promosi yang digunakan Studio Satu Metro TV, hanya berupa brosur dan melalui website resmi PT. Metro TV, Dengan mengandalkan sejumlah media informasi dan promosi tersebut di rasa belum cukup untuk di tunjukan kepada audience. Dalam studio satu, informasi dan promosi yang disampaikan cukup banyak, meliputi : kegiatan kameraman, pengenalan alat switcher, master control room dan lain-lain. Selain itu terdapat juga sejumlah kegiatan yang berlangsung di Studio Satu. Untuk itu video profile ini di rancang agar mampu memberikan informasi dan promosi yang akurat dan detail mengenai ruang lingkup Studio Satu secara menyeluruh. Adapun rancangan video profile Studio Satu ini bertujuan untuk menopang berbagai kegiatan seperti presentasi dengan klien ataupun partner dari PT Metro TV yang ingin mengetahui ruang lingkup Studio Satu secara menyeluruh, dan video ini juga untuk mendukung acara workshop ke kampus-kampus dalam rangka memperkenalkan Studio Satu Metro TV dan mengajak mahasiswa yang berminat menjadi salah satu crew di PT. Metro TV.

\section{LANDASAN TEORI}

\section{Konsep Dasar Perancangan.}

Menurut Binanto (2010 : 260) ${ }^{[5]}$ Menjelaskan bahwa perancangan adalah tahap pembuatan spesifikasi mengenai arsitektur program, gaya, tampilan, dan kebutuhan material atau bahan untuk program. Tahap ini biasanya menggunakan storyboard untuk menggambarkan deskripsi tiap scene lain dan bagan alir (flowchart) untuk menggambarkan aliran dari satu scene ke scene lain. 


\section{Konsep Dasar Promosi}

Menurut Desrianti,dkk (2014 : 425) ${ }^{[7]}$ Promosi adalah tindakan menginformasikan atau meningkatkan konsumen tentang spesifikasi produk atau merek. Promosi mempunyai kekuatan untuk menyampaikan pesan, dan diperlukan perancangan khusus agar promosi tersebut memiliki visual yang kuat dan menciptakan keserasian didalam rangkaian pemasaran, karena promosi adalah berkaitan langsung dalam upaya untuk memperkenalkan produk kepada konsumen dengan memikat hati mereka melalui pemberian kesan - kesan baik, yang mampu diingat dan dirasakan oleh konsumen.

\section{Konsep DasarCompany Profile}

Menurut Maimunah, dkk. (2012 : 284) ${ }^{[10]}$ Company Profile adalah sebuah aset suatu lembaga atau perusahaan yang dapat digunakan untuk meningkatkan suatu image atau citra dari perusahaan untuk menjalin kerjasama dengan relasi perusahaan, lembaga dan instansi yang terkait lainnya.

\section{Konsep Dasar Media}

\section{Pengertian Project}

Menurut Priyatno (2010 : 35) $)^{[13]}$, Project adalah susunan klip video, gambar, atau musik di timeline atau storyboard yang sedang dalam pengeditan.

\section{Pengertian Media}

Menurut Desrianti, dkk (2012 : 133) ${ }^{[6]}$ Media adalah segala bentuk yang digunakan untuk menyalurkan informasi. Pengertian media yang diberikan AECT (Association for education communication and tecnology) ini menunjukkan bahwa istilah "media" memiliki makna yang sangat umum.

\section{Konsep Dasar Multimedia Audio Visual and Broadcasting Pengertian Multimedia}

Menurut Arriesanti, dkk (2014 : 194) ${ }^{[2]}$ Multimedia adalah penggunaan komputer untuk menyajikan dan menggabungkan teks, suara, gambar, animasi, dan video dengan alat bantu (tool) dan koneksi (link) sehingga pengguna dapat melakukan navigasi, berinteraksi, berkarya, dan berkomunikasi. Multimedia sering digunakan dalam dunia hiburan, selain dari dunia hiburan, Multimedia juga dimanfaatkan dalam dunia pendidikan dan bisnis. Di dunia pendidikan, multimedia digunakan sebagai media pengajaran, baik dalam kelas maupun secara sendiri - sendiri. Di dunia bisnis, multimedia digunakan sebagai media profil perusahaan, profil produk, bahkan sebagai media informasi dan pelatihan dalam sistem $e$ learning.

Multimedia itu juga di artikan sebagai, suatu gambar dan video yang sudah dalam tahap editing dan sudah dapat di nikmati. Multimedia di bagi menjadi 2 bagian yaitu, multimedia content production dan multimedia communication. Dalam multimedia jika tak ada gambar dan hanya suara belum bisa disebut sebagai multimedia begitupun sebaliknya.

\section{Pengertian Audio}

Menurut Atmohoetomo (2010 : 18) ${ }^{[3]}$, Perkembangan teknologi dunia audio visual telah banyak mewarnai kehidupan manusia dari berbagai aspek kehidupan Modernisme yang di anggap sebagai puncak peradaban manusia dengan dikumandangkan rasionalisme, ternyata dengan ditemukannya "teknologi digital" menggeser "logika matematis". Dengan demikian akan terjadi ketidak jelasan antara "akal manusia" dengan "akal buatan" dan yang tejadi adalah jarak "rohani" yang terjadi sebatas dari layar 
monitor ke mata, kini lebih dekat sampai ke lensa mata, dan semakin dekat lagi hingga "diri kita" masuk ke mesin-mesin canggih melalui perangkat lunak Cyber dan Virtual.

Audio adalah suatu output suara yang di hasilkan oleh media tertentu dan dapat didengarkan dengan hasil yang jelas. Contoh alatnya adalah speaker. Jika kita menonton sebuah film maka kita juga membutuhkan audio ini agar menjadi lebih menarik dan bagus. Multimedia tidak akan lengkap jika tanpa audio (suara). Audio bisa berupa percakapan, musik atau efek suara.

\section{Pengertian Video}

Menurut Rahardja, dkk (2012 : 133) ${ }^{[14]}$ Video adalah teknologi menangkap, merekam, memproses, mentransmisikan dan menata ulang gambar bergerak.

Menurut Ayuningtyas (2011:7) $)^{[4]}$, video merupakan gabungan gambar-gambar mati yang dibaca berurutan dalam suatu waktu dengan kecepatan tertentu. Gambar-gambar yang digabung tersebut dinamakan frame dan kecepatan pembacaan gambar disebut dengan frame rate, dengan satuan fps (frame per second). Karena dimainkan dalam kecepatan yang tinggi maka tercipta ilusi gerak yang halus, semakin besar nilai frame rate maka akan semakin halus pergerakan yang di tampilkan.

Kesimpulannya video adalah gabungan gambar-gambar yang tersusun secara baik dalam satu waktu dengan kecepatan tertentu dan menghasilkan gambar gerak dengan dimensi yang berbeda.

\section{Pengertian Broadcasting}

Menurut Arifin (2011:9) ${ }^{[1]}$, Broadcasting adalah kegiatan dalam cara menyampaikan pesan, ide, hasrat, kepada khalayak dengan menggunakan fasilitas frequency, dengan kata lain dunia broadcasting adalah merupakan suatu kegiatan penyiaran yang dilakukan oleh seorang penyiar. Broadcasting merupakan dunia penyiaran, dan ini dapat dikatakan suatu kegiatan yang senantiasa selalu menarik perhatian khalayak masyarakat luas, baik secara audio dan visual.

\section{Konsep Dasar Video Profile}

Menurut Kuswandi (2011 : 47) ${ }^{[9]}$ Video profile adalah sebuah gambaran informasi tentang riwayat seseorang atau sebuah instansi perusahaan yang telah mencapai suatu pencapaian kesuksesan dalam hal produksi atau hasil karya yang telah dihasilkan dan diterima di kalangan masyarakat umum. Informasi tersebut disebarkan berbentuk audio visual atau video.

\section{Konsep Dasar Data \\ Pengertian Data}

Menurut Sunarya, dkk (2013 : 81) ${ }^{[17]}$ Data adalah sesuatu yang belum mempunyai arti bagi penerimanya dan masih memerlukan adanya suatu pengolahan. Data bisa berupa suatu keadaan, gambar, suara, huruf, angka, matematika, bahasa ataupun simbol - simbol lainnya yang bisa kita gunakan sebagai bahan untuk melihat lingkungan, obyek, kejadian ataupun suatu konsep.

MenurutYakub (2012 : 5) ${ }^{[18]}$ Data adalah deskripsi kenyataan yang menggambarkan adanya suatu kejadian (event), data terdiri dari fakta (fact) dan angka yang secara relatif tidak berarti bagi pemakai.

\section{Literatur Review}

1. Perancangan Video Profile yang dilakukan oleh Al Baihaqi (2012 ${ }^{[15]}$ STMIK Raharja. Untuk menunjang media informasi dan promosi pada SMA CITRA ISLAMI TANGERANG Saat ini sarana yang digunakan masih dalam bentuk media cetak dan 
dinilai dari pihak sekolah masih belum efektif, untuk itu kedepannya dari pihak sekolah menghendaki bentuk media berupa video profile sebagai penunjang kegiatan promosi dan informasi yang berisikan tentang fasilitas, keunggulan, sistem pembelajaran, kualitas pengajar, prestasi, kegiatan ekstrakulikulerdan keunggulan yang dimiliki SMA Citra Islami Tangerang secara lengkap dengan tampilan audio visual yang menarik, dengan tujuan meningkatkan citra atau image sekolah di masyarakat dan meningkatkan kuantitas jumlah calon siswa yang mendaftar setiap tahunnya.Tujuan dari penelitian ini diharapkan dengana danya media video profile diharapkan dapat meningkatkan target dalam perolehan calon siswa baru untuk bergabung bersama SMA Citra Islami.

2. Perancangan Video Profile yang dilakukan oleh Ningsih (2010) ${ }^{[11]}$.pada PG - TK PERMATA INSANI ISLAMIC SCHOOL. Penelitian tersebut menjelaskan tentang teknik cara pembuatan video profile dan bentuk media berupa video profile sebagai penunjang kegiatan promosi dan informasi yang berisikan tentang fasilitas, keunggulan, sistem pembelajaran, kualitas pengajar, prestasi, keunggulan yang dimiliki PG TK Permata Insani Islamic School.

3. Penelitian yang dilakukan oleh Parmania(2014) ${ }^{[12]}$, Media Company Profilepada PT. TELKOM AKSES JAKARTA. Menjelaskan tentang struktur lembaga telekomunikasi dan jaringan internet di seluruh Indonesia dan macam-macam tipe dan jenis jaringan maupun koneksi yang di kemas untuk diinformasikan kepada masyarakat luas.

4. Media Profile yang dilakukan Miranti (2012) ${ }^{[10]}$ STMIK Raharja, Untuk meningkatkan mutu dan citra SMA NEGERI 6. Media Teknologi dan informasi yang terus berkembang yang direalisasikan melalui berbagai hal seperti koran, majalah dan lain-lain. Namun pada saat ini masyarakat gemar menerima informasi melalui media informasi yang berupa audio visual. Dalam hal ini penyampaian informasi yang dilakukan oleh SMA Negeri 6 Tangerang hanya menggunakan media cetak, seperti brosur, famplet, spanduk, banner dan website sederhana. Tujuan dari penelitian ini yaitu untuk memberikan solusi dari permasalahan yang dihadapi petugas penerimaan siswa baru dalam hal memberikan informasikepadamasyarakat.

5. Penelitian Company Profile yang dilakukan oleh Septian (2014) [16], pada RSIA MURNI ASIH berbentuk video merupakan sarana penting sebagai penunjang informasi dan sangat mungkin dirancang untuk pembuatan media company profile, selain sebagai penunjang informasi mengenai sejarah, kualitas, mutu serta kelebihan dan lainnya, media company profile juga bisa disesuaikan dengan tujuan serta demi kelancaran dan efektifitas penyampaian informasi seputar kesehatan sudah saatnya memiliki media informasi dalam bentuk video profile yang menarik dengan visual atau gambar-gambar yang memperjelas sebuah informasi.

Berdasarkan analisa terhadap 5 literature review sebelumnya maka dapat ditarik kesimpulan bahwa media video profile sangat dibutuhkan dalam menunjang informasi dan promosi suatu perusahaan, karena media video profile menampilkan rangkaian audio visual berupa gambar, video, dan musik secara terangkai atau berurutan dengan konsep tertentu yang digunakan untuk keperluan seperti untuk memperkenalkan, menginformasikan, dan mempromosikan ruang lingkup Studio Satu PT. Metro TV secara detail dengan menyajikan informasi up to date sesuai perkembangan perusahaan saat ini, sehingga mampu memenuhi kebutuhan para audience akan informasi. Melalui perancangan video profile ini, diharapkan dapat meningkatkan image Studio Satu PT. Metro TV. 


\section{METODE PENELITIAN}

Metode penelitian yang dilakukan, dalam merancang Video Profile pada Studio Satu PT METRO TV adalah sebagai berikut : (1) Metode Analisa Permasalahan didapatkan dari hasil interview yang dilakukan pada Studio Satu PT. Metro TV. (2) Metode Pengumpulan Data dilakukan dengan cara Observasi, Interview, dan Studi Pustaka. (3) Metode Analisa Perancangan Media. Media video profile yang dibutuhkan oleh PT. Media Televisi Indonesia, akan diproduksi dengan menggunakan aplikasi program komputer grafis diantaranya : Adobe Premiere Pro CS 3, Adobe After Effects CS 3, dan Adobe Photoshop CS 3. (4) Metode Konsep Produksi Mavib (KPM) yang meliputi : Pre production, Production, dan Post production

\section{Konsep Produksi Media (Kpm)}

Video profile ini dirancang dengan tahap yang ada pada produksi MAVIB (Multimedia Audio Visual and Broadcasting). Video profile ini telah disusun dan di diskusikan dengan stakeholder agar dapat bermanfaat bagi Studio Satu. Kemajuan dari MAVIB tersebut akan menghasilkan suatu media audio visual yang menarik untuk disajikan kepada audience. Dalam video ini digabungkan dengan animasi, suara, dan musik sehingga tampilan lebih menarik dan tidak membosankan. Tahapan dari Konsep Produksi MAVIB tersebut dimulai dari Preproduction, Production dan Postproduction.

\section{KPM}

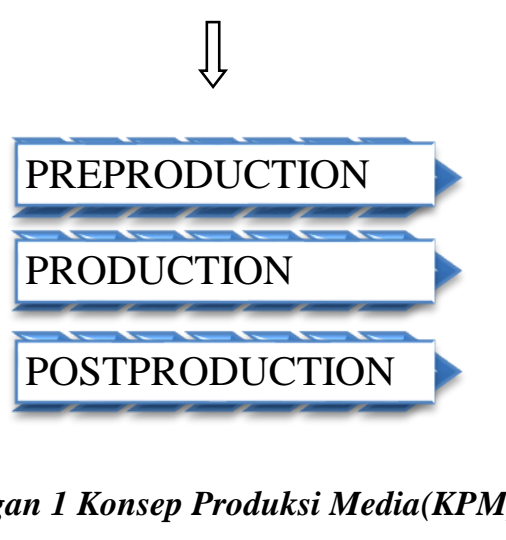

\section{Pre Production}

Preproduction merupakan tahap dimana sebuah project atau produksi akan dimulai. Pada tahap ini membutuhkan perencanaan yang sudah cukup siap, seperti penyusunan naskah, pembuatan skenario, dan pembuatan time schedule, dan juga pembuatan synopsisdan storyboard untuk kelancaran dalam pembuatan sebuah video profile. Setelah itu baru ditentukan alat-alat yang akan digunakan beserta pemainnya, dan crew yang berada dalam pembuatan produksi ini. Kemudian dilanjutkan dengan pengumpulan data melalui observasi maupun wawancara dengan pihak terkait, lalu persiapan konsep dimulai dari dituangkannya ide - ide bagaimana menampilkan video profile yang menarik bagi audience. Untuk lebih jelasnya di ilustrasikan pada bagan berikut ini : 


\section{PREPRODUCTION}

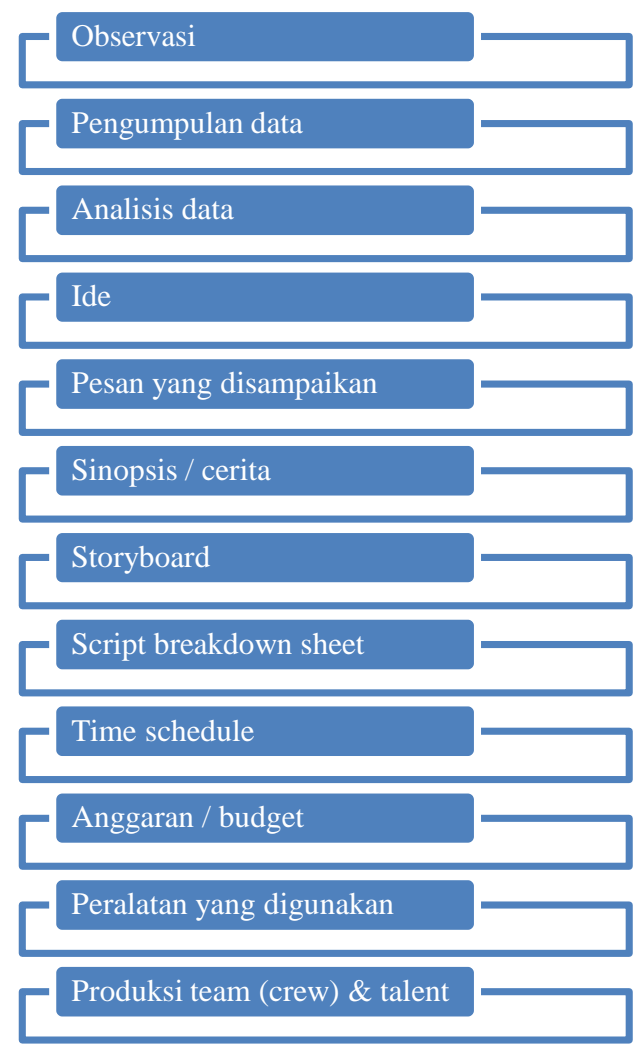

Bagan 2

Tahap Preproduction

\section{Observasi}

Dalam implementasi media video profile penunjang promosi dan informasi pada Studio Satu PT .Metro TV hanya melalui telepon dan walk indi Jl. Pilar Mas Raya Kav A-D kedoya Selatan- Kebon Jeruk, Jakarta 111015, dan dapat melalui website di www.metrotvnews.com. Dengan memanfaatkan teknologi yang modern pada saat ini, maka media informasi yang akan digunakan adalah media video profile. Dengan konsep yang lebih modern dan menarik maka diharapkan dapat mudah diakses dan dipahami oleh masyarakat luas. Video profile ini dirancang dengan tampilan yang cukup menarik dengan menggunakan berbagai efek yang cukup bagus, dengan adanya video profile ini diharapkan akan memudahkan audience dalam mendapatkan informasi. Observasi yang dilakukan adalah dengan mendatangi secara langsung, untuk mendapatkan informasi yang dibutuhkan dalam penelitian. Setelah dilakukan penelitian, dalam proses penyampaian informasi tersebut dapat diimplementasikan melalui web dan brosur. Untuk itu dalam proses pembuatan video profile ini perlu memperhatikan proses pengambilan gambar, editing, dubbing, serta efek animasi yang dipilih, agar dapat di nikmati dan menarik.

Ide

Setelah melakukan beberapa analisa data dan pengumpulan data secara observasi, wawancara dan studi pustka, tahap berikutnya adalah penentuan ide maupun gagasan yang nantinya akan 
disimpulkan dalam tahap pembuatan video profile ini, agar nantinyavideo profile ini dapat berguna dan bermanfaat bagi masyarakat luas dan khusunya bagi PT. Metro TV. Dalam pembuatan video tersebut memiliki banyak keunggulan daripada melalui website ataupun brosur. Karena dalam penyampaian melalui video data memungkinkan informasi yang di terima audience, lebih akurat karena dipadukan dengan gambar dan suara, sehingga tampilan akan menjadi lebih menarik dan tidak membosankan. Multimedia yang menampilkan fasilitas-fasilitas dan memaparkan segala sesuatu yang mencangkup tentang Studio Satu Metro TV. Media informasi yang telahdibuat mengambil inti dari ide tersebut.

\section{Sinopsis / Alur Cerita}

Sinopsis adalah bagian dari alur cerita yang menghubungkan jalan cerita pertama hingga terakhir, dan digabungkan sehingga menjadi satu jalan cerita yang menarik. Sinopsis atau alur cerita pembuatan video profile ini adalah :

"Metro TV adalah televisi berita 24 jam pertama di indonesia yang mulai mengudara pada tanggal 25 November 2000 Metro TV merupakan salah satu anaka perusahaaan dari MEDIA GROUP yang dimiliki oleh Surya Paloh. Surya Paloh merintis usahanya di bidang pers sejak mendirikan surat kabar harian PRIORITAS. Metro TV dapat ditangkap secara terestial di 280 kota tersebar di Indonesia, yang dipancarkan dari 52 transmisi. Selain secara terestial, siaran Metro TV dapat tangkap melalui televisi kabel di seluruh Indonesia, melalui Satelit Palapa 2 ke seluruh negaranegara ASEAN, termasuk Hongkong, Cina Selatan, India, Taiwan, Macau, Papua New Guinea, dan sebagian Australia serta Jepang.

Metro TV melakukan kerjasama dengan beberapa televisi asing yaitu kerjasama dalam pertukaran berita, kerjasama pengembangan tenaga kerja dan banyak lagi. Stasiun televisi tersebut adalah CCTV, Channel 7 Australia, dan Voices Of America (VOA), Channel News Asia(CNN) dan AlJazeera Qatar. Selain berkerja sama dengan stasiun televisi Internasional, Metro TV juga memliki Internasional kontributor yang tersebar di Jepang, China, USA, dan Inggris. Dengan kerja sama internasional ini Metro TV berusaha untuk memberikan sumber berita mengenai keadaan dalam negeri yang dapat dipercaya dan komprehensif kepada dunia luar dan juga hal ini mendukung Metro $T V$ untuk menjadi media yang secara cepat, tepat, dan cerdas dalam mendapatkan beritanya.

PT Metro TV mempunyai visi dan misi yang cukup baik agar dapat terlaksananya kebutuhan maupun kualitas perusahaan PT Metro TV. Di studio satu ini pesan yang di sampaikan ke masyarakat melalui beberapa tahapan agar informasi yang di sampaikan akan berguna dan bermanfaat bagi masyarakat, dengan slogan Knowledge To Elevate, mengajak masyarakat untuk selalu memperbaharui pengetahuan dan informasi yang ada di Indonesia maupun dunia.

\section{Story Board}

Tabel 1Storyboard Video Profile Studio Satu PT.Metro TV

\begin{tabular}{|c|c|c|}
\hline No & Board & Keterangan \\
\hline 1 & & $\begin{array}{l}\text { Bumper Opening } \\
\text { Bumper yang digunakan sebelum memasuki tahap bumper pengenalan } \\
\text { studio satu }\end{array}$ \\
\hline
\end{tabular}




\begin{tabular}{|c|c|c|}
\hline 2 & 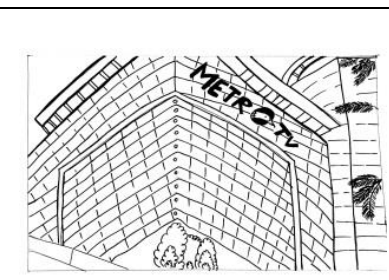 & $\begin{array}{l}\text { Ext/Gedung Perusahaan/Siang/Profile METRO TV } \\
\text { gedung metro tv yang tampak terlihat dari posisi depan pada saat siang } \\
\text { hari }\end{array}$ \\
\hline 3 & & $\begin{array}{l}\text { Ext/Tampilan Depan Pintu Masuk Studio Satu/Siang/ProfilPT.Metro TV } \\
\text { Seorang satpam/security yang sedang berjaga dan hendak masuk kedalam } \\
\text { ruangan khusus untuknya }\end{array}$ \\
\hline 4 & 船 & $\begin{array}{l}\text { Int/Studio Satu/Siang/Kegiatan Di Resepsionis Studio Satu } \\
\text { Dari dalam ruangan khusus penjaga keamanan terlihat dua orang satpam } \\
\text { yang sedang bertugas dan terlihat seperti melakukan }\end{array}$ \\
\hline 5 & & $\begin{array}{l}\text { Int/Ruangan Studio Satu/Siang/ } \\
\text { Kegiatan Siaran Metro Siang } \\
\text { Dalam acara metro siang, seorang pembawa acara dan seorang } \\
\text { cameraman sedang betugas untuk memberikan informasi dan berita yang } \\
\text { aktual }\end{array}$ \\
\hline 6. & 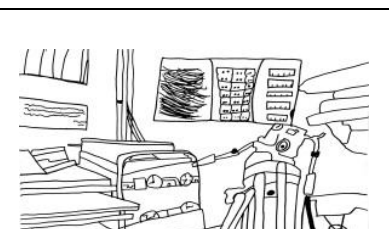 & $\begin{array}{l}\text { Int/Ruangan/ } \\
\text { Siang/Peralatan Siaran Studio Satu } \\
\text { Ruangan khusus yang telah di sediakan untuk menaruh sejumlah alat-alat } \\
\text { yang dibutuhkan untuk melakukan liputan langsung maupun tidak } \\
\text { langsung }\end{array}$ \\
\hline 7. & & $\begin{array}{l}\text { Ext/Suasana Teras Studio Satu/Siang } \\
\text { /Kegiatan karyawan sedang berbincang dengan } \\
\text { Beberapa orang }\end{array}$ \\
\hline 8. & & $\begin{array}{l}\text { Int/Ruang Camstore/Siang/ } \\
\text { kamera dalam } \\
\text { loker yang bisa di pinjamkan saat } \\
\text { liputan di luar } \\
\text { Terlihat beberapa kamera untuk mencari berita ataupun liputan di luar dari } \\
\text { gedung metro tv yang terletak di dalam loker yang telah disediakan }\end{array}$ \\
\hline
\end{tabular}




\begin{tabular}{|l|l|l|}
\hline 9. & $\begin{array}{l}\text { Int/Kantin/Siang/Kantin tempat Studio Satu } \\
\text { Kantin untuk studio satu ini berguna untuk mempermudah para karyawan } \\
\text { maupun klien untuk bersantai pada saat beristirahat sambil menyantap } \\
\text { makanan }\end{array}$ \\
\hline 10. & $\begin{array}{l}\text { Bumper closing } \\
\text { Studio one Documentary. } \\
\text { Tampilan akhir dari projek yang digunakan sesudah opening. }\end{array}$ \\
\hline
\end{tabular}

\section{Production}

Pada tahap production sendiri adalah sebuah produksi yang sudah memasuki tahap penyusunan dan pengeditan dan menghasilkan sebuah project video. Dalam tahapan ini harus dilihat pula kerjasama antara crew dan talent untuk perwujudan hasil rumusan dari storyboard, naskah, dan skenario yang telah dibuat pada tahap pre production sebelumnya. Production memiliki empat tahapan berupa Perencanaan Multimedia, Audio, Visual, dan yang terakhir Perencanaan Broadcasting. Pada tahap Production ini, unsur yang terdapat dalam

pre production seperti naskah, sinopsis, storyboard maupun rundown mendapat peran yang besar untuk tahap berikutnya yaitu production, karena storyboard penting dalam penentuan titik-titik pengambilan gambar yang cocok dan bagus. Sedangkan untuk sinopsis sendiri digunakan untuk menentukan alur cerita dan kalimat yang akan digunakan nantinya, agar kata maupun kalimat didalamnya berisifat formal dan dapat di mengerti oleh masyrakat luas. Berikut merupakan bagan dari tahap proses Production.

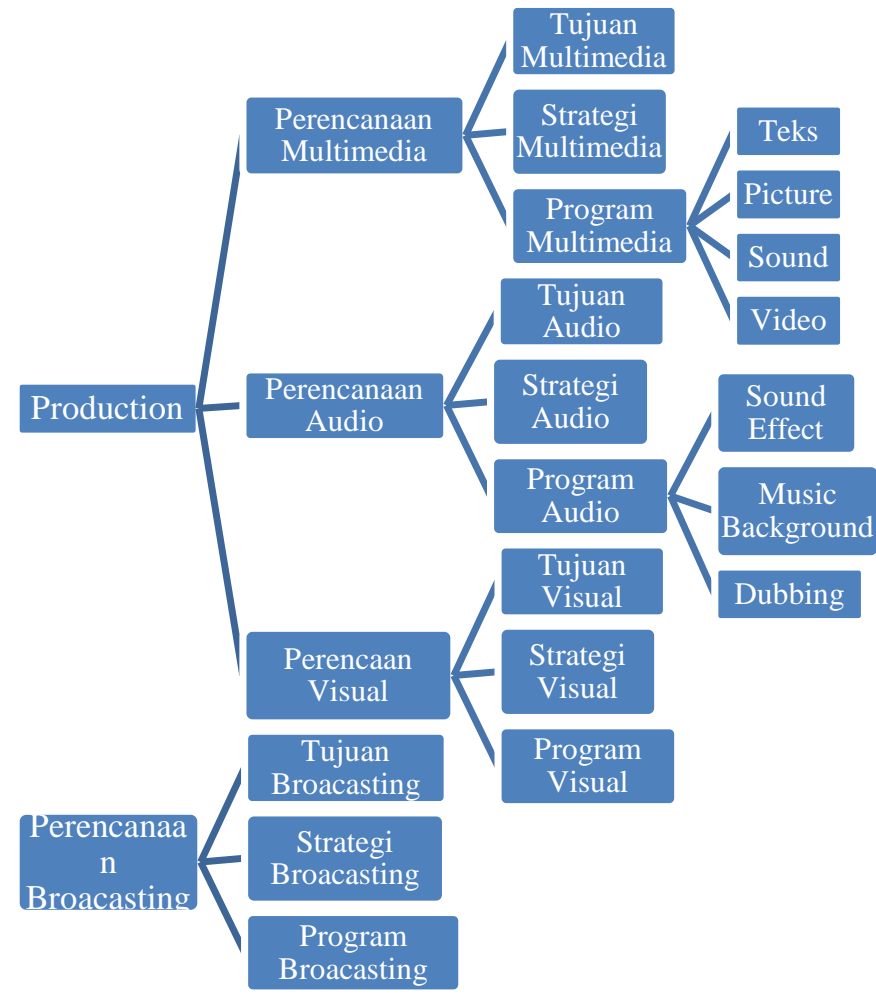




\section{Bagan 4.3 \\ Tahap Production}

\section{Postproduction}

Postproduction merupakan tahapan terakhir diantara proses-proses yang sebelumnya. Dari proses awal preproduction, lalu masuk pada tahapan production, dan berakhir di tahap post production. Pada tahap post production ini terdapat terdapat proses digitalizing, editing, finishing, mixing, art directing dan designing. Dengan adanya tahap terakhir ini, diharapkan target yang akan dicapai dapat terwujud dan terlaksana.

Tahap postproduction adalah proses finishing sebuah karya sampai menjadi sebuah video yang utuh dan mampu untukmenyampaikan sebuah cerita atau pesan kepada audience. Dalam tahap finishing ini, proses editing sedang dilaksanakan oleh editor. Dimana semua gambar gerak, teks dan suara di gabungkan sehingga menghasilkan suatu format penyampaian informasi yang cukup baik dan jelas. Berikut bagan dari tahapan postproduction:

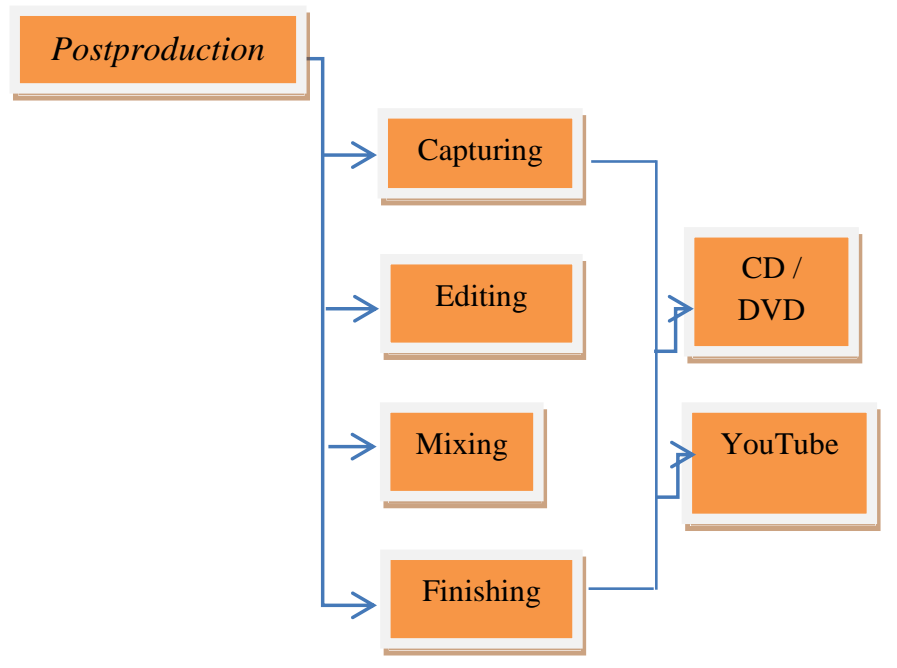

Bagan 3 Post Production

\section{Story Board Tampilan isi}

Story Board adalah sebuah penyusunan beberapa gambar secara bertahap sesuai dengan aslinya untuk keperluan shooting atau pengambilan gambar. Pengambilan storyboard harus sangat memperhatikan detail gambar yang diambil dan memberikan keterangan waktu, gambar maupun posisi diluar ruangan atau di dalam ruangan.

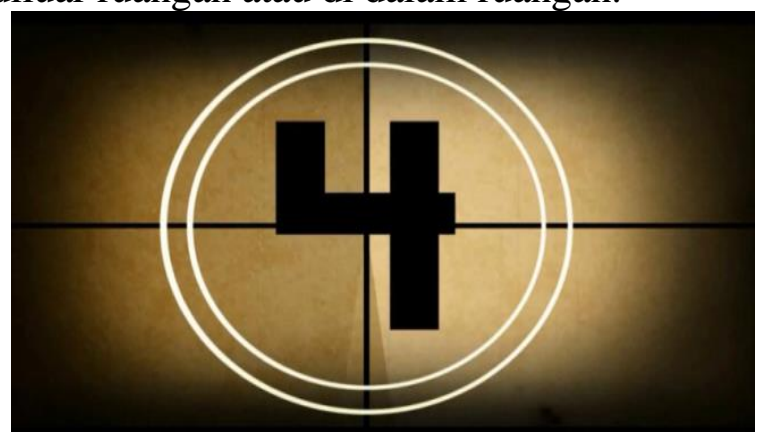

Gambar 1

Bumper Opening.

Bumper opening yang digunakan sebelum memulai video profie. 


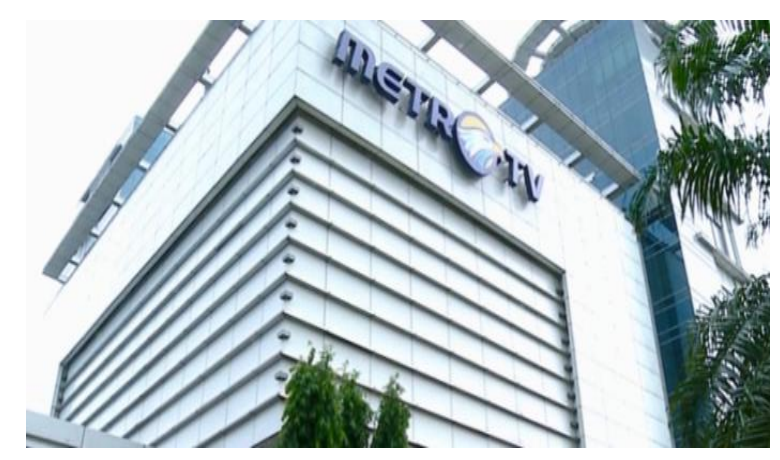

Gambar 2

Ext/Gedung Perusahaan/Siang/Profile METRO TV Nampak gedung perusahaan Metro TV saat siang hari dari luar ruangan

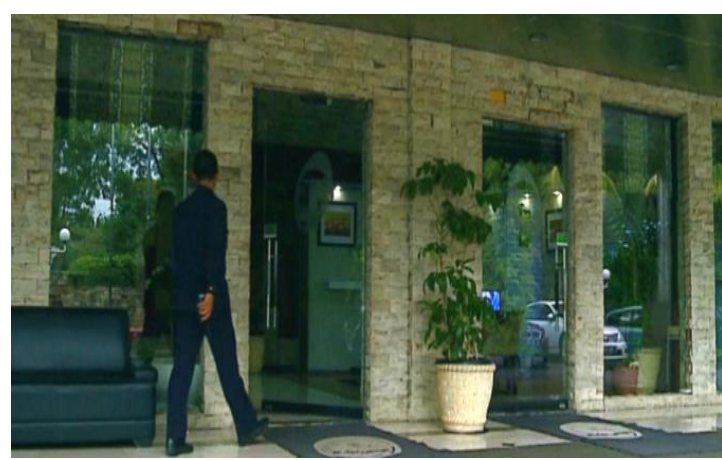

Gambar 3

Ext/Tampilan Depan Pintu Masuk Studio Satu/Siang/Profile Studio Satu Tampilan yang menunjukkan seorang satpam sedang menuju pintu masuk studio satu

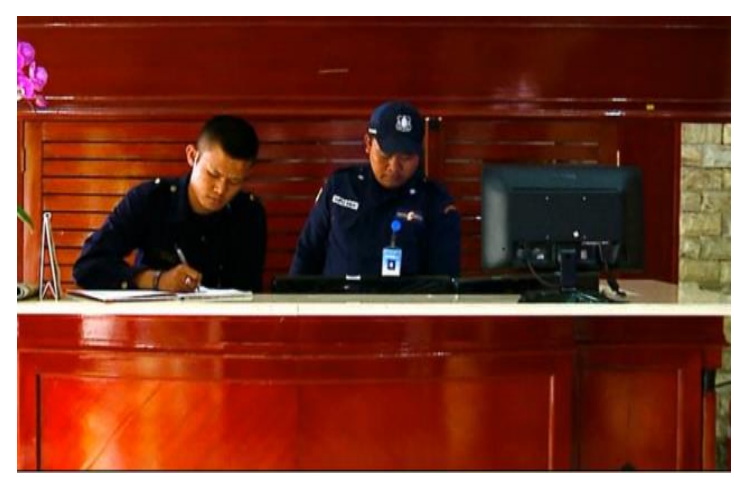

Gambar 4

Int/Studio Satu/Siang/Kegiatan

di Resepsionis Studio Satu.

Suasana resepsionis dan satpam yang berjaga di studio satu. 


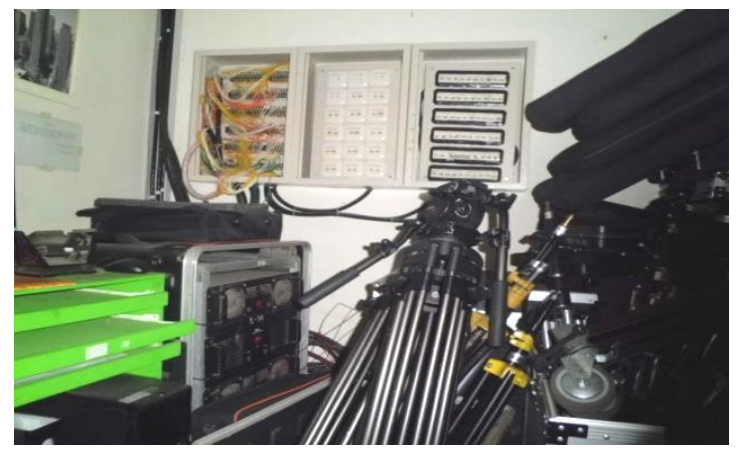

Gambar 5

Int/Ruangan/Siang/Peralatan Siaran Studio Satu. Ruangan khusus untuk menyimpan peralatan siaran di Studio Satu.

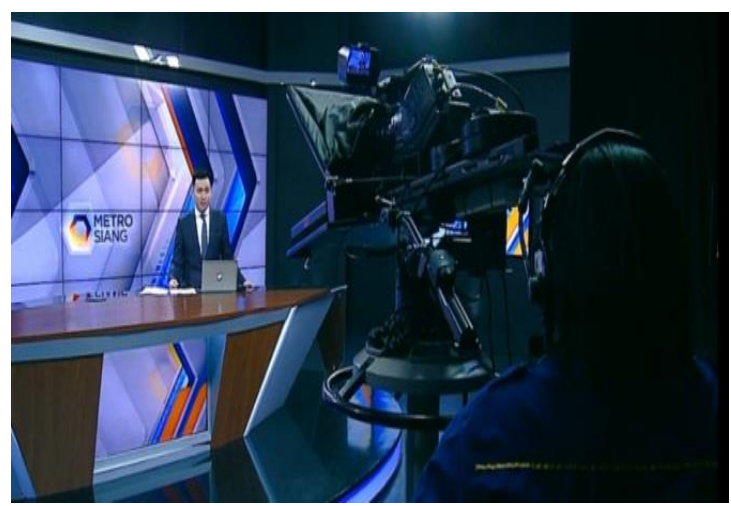

Gambar 6

Int/Ruangan Studio Satu/Siang/Kegiatan Siaran.

Metro Siang yang berlangsung selama 60 menit memberikan informasi/peristiwa yang tengah hangat dibicarakan publik.

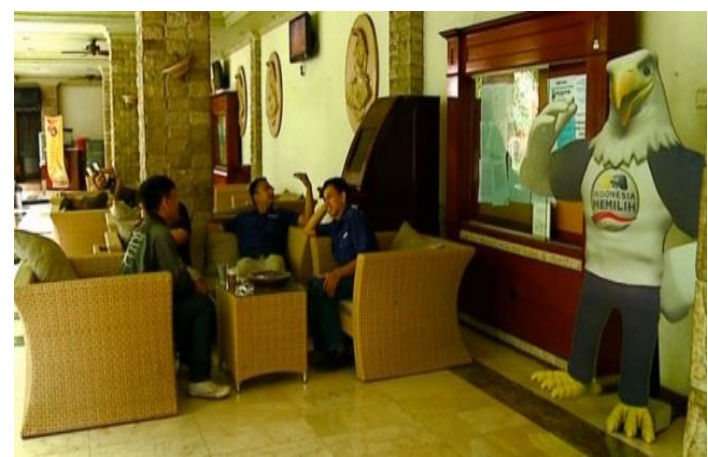

Gambar 7

Ext/Suasana Teras Studio Satu/Siang/Kegiatan karyawan sedang berbincang. Tampilan teras tempat para karyawan bersantai dan berbincang di waktu kosong pada saat bekerja. 


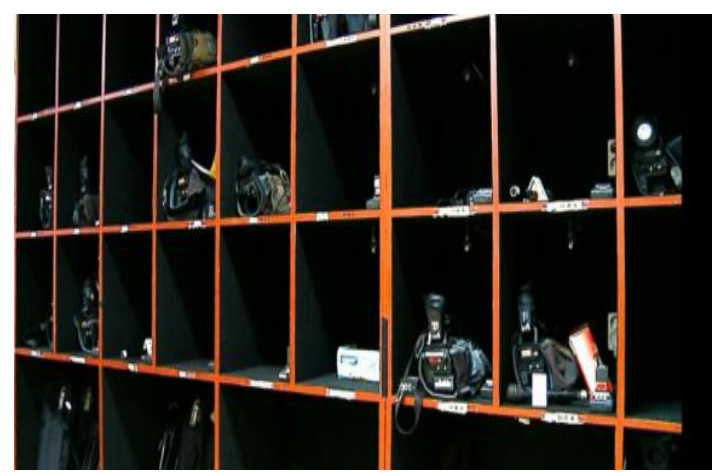

Gambar 8

Int/Ruang Camstore/Siang/kamera dalam loker yang bisa di pinjamkan saat liputan di luar. Kamera yang disusun rapi didalam loker yang dapat dipinjamkan untuk liputan diluar.

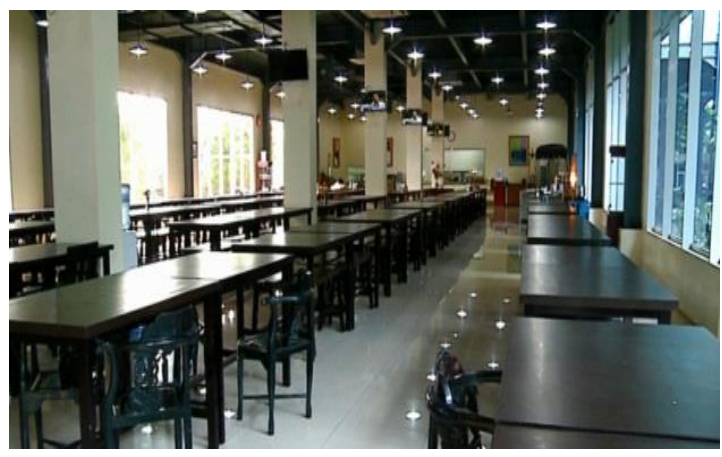

Gambar 9

Int/Kantin/Siang/Kantin Studio Satu

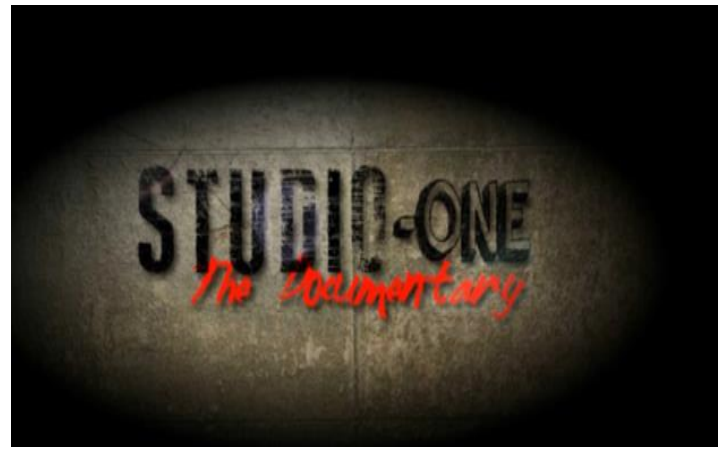

Gambar 10

Bumper closing Studio one Documentary.

Tampilan akhir dari projek video profile

\section{KESIMPULAN}

Media yang tepat untuk menunjang informasi dan promosi Studio Satu PT. Metro TV adalah dengan menggunakan video profile. Dengan adanya media video profile ini diharapkan dapat menunjang beberapa akses informasi, dan juga keperluan untuk menunjang kegiatan workshop yang diadakan oleh PT. Metro TV khususnya pada studio satu. Video profile ini juga diharapkan akan bermanfaat untuk pembelajaran bagi seluruh karyawan yang sedang mendalami ilmu dan teknikal tentang broadcasting. Dengan memberikan informasi akurat dan detail dengan disertai penyampaian informasi yang jelas, sehingga dapat berguna 
dan bermanfaat bagi audience yang berminat untuk mengetahui informasi tentang Studio Satu PT. Metro TV. Adapun penyampain informasi ini meliputi ruang lingkup pada Studio Satu, dan kegiatan yang berada dalam Studio Satu seperti aktifitas kegiatan siaran berita, kegiatan dalam ruang $C C U$ ataupun ruang Master Control room. Dalam merancang Video Profile yang menarik dan dapat meningkatkan image Studio Satu PT. Metro TV, memerlukan strategi visual yaitu dengan memperhatikan gambar, teks, audio serta efek-efek yang akan digunakan agar tampilan dapat terlihat lebih menarik, sehingga lebih diminati audience, dan juga dengan menampilkan informasi yang akurat, sehingga mampu memenuhi kebutuhan para audience akan informasi. Melalui perancangan video profile ini diharapkan dapat meningkatkan image Studio Satu PT. Metro TV.

\section{DAFTAR PUSTAKA}

[1] Arifin Eva, 2011 “Menjadi Sutradara Televisi : Dengan Single dan Multi Camera "Jakarta : Grasindo.

[2] Arriesanti, Hani Dewi, Yusup Muhammad, Marcelina Ceria. 2014.Penerapan Multimedia Audio Galery Ilearning Community and Services (Magics) Sebagai Media Penyimpanan. Journal CCIT Vol.7 No.2-Januari 2014. Tangerang: Perguruan Tinggi Raharja.

[3] Atmohoetomo, Soegito, 2010 "Menjadi Sutradara Televisi : Dengan Single dan Multi Camera" Jakarta : Grasindo.

[4] Ayuningtyas, Melvy, 2011 "Ngedit Video Dengan Adobe Premiere CS 3 " Bekasi :DuniaKomputer.

[5] Binanto, Iwan. 2010. Multimedia Digital (Dasar Teori dan Pengembangannya). ANDI : Yogyakarta.

[6] Desrianti, Dewi Immaniar Raharja Untung, Mulyani Reni. Audio Visual As One Of The Teaching Resources On Ilearning. Journal CCIT Vol.5 No.2-Januari2012. Tangerang: Perguruan Tinggi Raharja.

[7] Desrianti, Dewi ImmaniarSudaryono, Dwi Ayu Ningrum. 2014. Enriching Media Merchandise Sarana Penunjang Promosi Studi Kasus Pada Bookstore. Journal CCIT Vol. 7 No.3 - Mei 2014. Tangerang : Perguruan Tinggi Raharja.

[8] Kuswandi, Wawan. 2010. Komunikasi Massa Sebuah Analisis Media Televisi. Jakarta : Rineka Cipta.

[9] Maimunah, LusyaniSunarya, Nina Larasati. 2012. Media Company Profile Sebagai Sarana Penunjang Informasi dan Promosi. Journal CCIT Vol.5 No.3 - Mei 2012. Tangerang : Perguruan Tinggi Raharja.

[10] Miranti, Devi Dina. 2012. Perancangan Media Video Profile Sebagai Penunjang 
Informasi Untuk Meningkatkan Mutu Dan Citra SMA Negeri 6 Tangerang. Tangerang : Perguruan Tinggi Raharja.

[11] Ningsih, Nur Putriana Desy.2014. Perancangan Video Profile Sebagai Media Informasi Dan Promosi Pada PG-TKPermata Insani Islamic School. Tangerang : Perguruan Tinggi Raharja.

[12]Parmania, Dwi Fitri. 2014. Perancangan Video Company Profile Sebagai Media Penunjang Informasi Dan Promosi Pada PT. Telkom Akses Jakarta. Tangerang : Perguruan Tinggi Raharja.

[13]Priyatno, Dwi. 2010. Create Your Film. Yogyakarta : Multicom.

[14] Rahardja, Untung, dkk. 2012. "Audio Visual As One Of The Teaching Resources On Ilearning “ Journal CCIT Vol 5 No. 2. Tangerang :Perguruan Tinggi Raharja.

[15] Romly Acmad, Al Baihaqi. 2012. "Perancangan Video Profile Sebagai Penunjang Media Informasi Dan Promosi Pada SMA Citra Islami Tangerang "Tangerang : Perguruan Tinggi Raharja .

[16] Septian, Vikri.2014. Perancangan Video Company Profile Pada RSIA Murni Asih Sebagai Media Promosi. Tangerang : Perguruan Tinggi Raharja.

[17] Sunarya, Lusyani, Radiyanto, Erna Susanti. 2013. Enriching Company Profile Sebagai Penunjang Media Informasi Dan Promosi Pada Perguruan Tinggi Raharja. Journal CCIT Vol. 7 No.1 - September 2013. Tangerang : Perguruan Tinggi Raharja.

[18] Yakub. 2012. Pengantar Sistem Informasi. Yogyakarta : Graha Ilmu. 